\title{
Biochemical characterization of 1-Cys peroxiredoxin from Antrodia camphorata
}

\author{
Lisa Wen • Hui-Ming Huang • Rong-Huay Juang • \\ Chi-Tsai Lin
}

Received: 25 April 2006 /Revised: 27 July 2006 / Accepted: 8 August 2006 / Published online: 14 November 2006

(C) Springer-Verlag 2006

\begin{abstract}
Antrodia camphorata is a unique medicinal mushroom found only in Taiwan. It has been used as a remedy for various diseases in folk medicine. Antrodia camphorata has been shown to exhibit antioxidative effects. Peroxiredoxins play important roles in antioxidation and cell signaling. A gene encoding an antioxidant enzyme, 1 -cysteine peroxiredoxin (1-Cys Prx), was identified in an expressed sequence tag database of the A. camphorata and cloned by polymerase chain reaction. The 1-Cys Prx cDNA (837 bp, accession no. AY870325) contains an open reading frame encoding a protein of 223 amino acid residues with calculated molecular mass of 25,081 Da. The deduced protein shared $44-58 \%$ identity with 1-Cys Prx from Homo sapiens, Bos taurus, and Saccharomyces cerevisia. The sequence surrounding the conserved cysteine DFTPVCTTE is conserved. The coding sequence was subcloned into a vector, pET-20b (+), and transformed into
\end{abstract}

Lisa Wen, Hui-Ming Huang, and Rong-Huay Juang contributed equally to this paper.

\footnotetext{
H.-M. Huang $\cdot$ C.-T. Lin $(\square)$

Institute of Bioscience and Biotechnology,

National Taiwan Ocean University,

2 Pei-Ning Rd.,

Keelung 202, Taiwan

e-mail: B0220@mail.ntou.edu.tw

L. Wen

Department of Chemistry, Western Illinois University,

1 University Circle,

Macomb, IL 61455-1390, USA

R.-H. Juang

Department of Biochemical Science and Technology,

National Taiwan University,

Taipei 106, Taiwan
}

Escherichia coli. The recombinant 1-Cys Prx was purified by $\mathrm{Ni}^{2+}$-nitrilotriacetic acid (Sepharose). The purified enzyme was characterized under various conditions. The enzyme is thermostable because its half-life of inactivation was $15.5 \mathrm{~min}$ at $60^{\circ} \mathrm{C}$. It was stable under alkaline $\mathrm{pH}$ range from 7.8 to 10.2 . The enzyme showed decreased activity with increasing concentration of imidazole. The enzyme is sensitive to trypsin and chymotrypsin treatment.

Keywords Mushroom Antrodia camphorata . Expression $\cdot 1$-Cys peroxiredoxin (1-Cys Prx)

\section{Introduction}

Peroxiredoxins (Prxs) constitute a family of peroxidases found in a variety of organisms from bacteria to mammals (Hofmann et al. 2002; Rhee et al. 2005a,b). The enzymes play important roles in antioxidation and cell signaling (Neumann et al. 2003; Rhee et al. 2005a,b). They exert their protective antioxidant role by reducing/detoxifying alkyl hydroperoxides and hydrogen peroxide using thiols as reductants (Bryk et al. 2000; Hillas et al. 2000). Thioredoxin peroxidase (TPx) is a peroxidase that reduces hydrogen peroxide with the use of electrons from thioredoxin (Trx) and contains two essential cysteines (Kang et al. 1998). All Prxs use the conserved redox active peroxidatic cysteine $\left(\mathrm{C}_{\mathrm{P}}\right)$ located at the $\mathrm{N}$-terminal portion of the molecule to reduce peroxides (Wood et al. 2003a,b). During the peroxidase reaction, the $\mathrm{C}_{\mathrm{P}}$ residue in the active site is oxidized to sulfenic acid $\left(\mathrm{C}_{\mathrm{P}}-\mathrm{SOH}\right)$, whereas hydrogen peroxide, peroxynitrite, and a broad range of alkyl hydroperoxides are reduced to water, nitrite, or the corresponding alcohol (Ellis and Poole 1997). Prxs are 
classified into two types, 1-Cys and 2-Cys, based on whether they contain one or two conserved Cys residues (Chon et al. 2005). The 2-Cys Prxs contain a second conserved resolving Cys $\left(\mathrm{C}_{\mathrm{R}}\right)$ residue at the $\mathrm{C}$-terminal portion of the molecule. The 2-Cys Prxs have been further subdivided into either typical or atypical types depending on the location of the $\mathrm{C}_{\mathrm{R}}$ residue. In typical 2-Cys Prxs, the $\mathrm{C}_{\mathrm{P}}-\mathrm{SOH}$ reacts with the $\mathrm{C}_{\mathrm{R}}-\mathrm{SH}$ residue located in the $\mathrm{C}$ terminal portion of the second subunit of the enzyme homodimer to form an intermolecular disulfide (Chae et al. 1994). In atypical 2-Cys Prxs, the $\mathrm{C}_{\mathrm{P}}$-SOH reacts with the $\mathrm{C}_{\mathrm{R}}$-SH residue within the same subunit forming intramolecular disulfide. The disulfide is then reduced by $\operatorname{Trx}$, glutaredoxin, or glutathione (Pak et al. 2002; Dietz 2003) completing the catalytic cycle. In the case of 1-Cys Prx, Cys-SH is oxidized by peroxide to $\mathrm{Cys}-\mathrm{OH}$ that can be reduced by a thiol such as dithiothreitol (DTT) (Pak et al. 2002).

Prx is one of the most important antioxidant enzymes. Treatment of L2 cells (a rat lung epithelial cell line) with an antisense oligonucleotide to 1-Cys Prx revealed that 1-Cys Prx can function in the intact cells as an antioxidant enzyme to reduce the accumulation of phospholipid hydroperoxides and prevent cell suicide by apoptosis (Pak et al. 2002). Under oxidative stress, PrxVI (a 1-Cys Prx) knockout mice were found to have lower survival rates, with more severe tissue damage in organs such as the kidney, liver, and lung. In PrxVI knockout animals, the gene expression levels of other antioxidant enzymes such as catalase, glutathione peroxidase, and manganese superoxide dismutase were not different from those of the wild-type mice, suggesting that PrxVI cannot be compensated for by these antioxidase genes (Wang et al. 2003; Immenschuh and Baumgart-Vogt 2005). Several in vitro and in vivo studies have implicated the potential of 2-Cys Prxs as either therapeutic targets or diagnostic biomarkers for major diseases. Prx I expression is elevated in most cancers, and it is believed to be a consequence of self-defense against tumorigenesis. The possibility that recombinant 2-Cys Prx proteins can be useful for cancer prevention has been proposed (Kang et al. 2005). Recombinant Prx I and Prx II have also been shown to exhibit antiviral activity by inhibiting HIV-1 replication (Geiben-Lynn et al. 2003). Cytosolic yeast Prxs, cPrxI, and cPrxII can act alternatively as peroxidases and molecular chaperones. It has been reported that oxidative stress and heat shock exposure of yeasts caused the cPrxI and II to shift from low molecular weight (MW) species to high MW complexes and triggered a peroxidase-to-chaperone functional switch (Jang et al. 2004). Therefore, a potential alternative use of recombinant 2-Cys Prx would be to prevent abnormal protein aggregation in the damaged neurons (Kang et al. 2005). Antioxidant enzymes that can restore misfolded proteins to their active conformations may play a role in promoting longevity (Gems and McElwee 2003).

Chinese cultures traditionally treat sickness with natural therapeutic ingredients rather than over-the-counter or prescription medication. In Asia, medicinal mushrooms believed to increase longevity in traditional practice have long been regarded as health foods. Antrodia camphorata is a unique medicinal mushroom species found only in the forests of Taiwan, which uses Cinnamomum kanehirai hay as its host. The fruiting body of $A$. camphorata has been used as a remedy for various diseases in folk medicine for many years. Therefore, this local mushroom is especially highly regarded in Taiwan. Antrodia camphorata has been shown to exhibit antioxidative (Hsiao et al. 2003), anticancer (Hseu et al. 2004; Hsu et al. 2005), and antihepatic (Hsiao et al. 2003; Song and Yen 2003) effects. Antrodia camphorata is also used as a health food in maintaining life expectancy. Although A. camphorata shows physiological activities with great potentials in medical applications, only a few scientific studies have been reported. This motivated us to establish ESTs (expression sequence tags) from fruit body of $A$. camphorata to search physiologically active components for medicinal use. We are particularly interested in antioxidant enzymes such as Prxs because this family of enzymes may be one of the important physiologically active components in A. camphorata responsible for maintaining human health and longevity. Here we report cloning and expression of an antioxidant enzyme, 1-Cys Prx cDNA, from A. camphorata (Ac-1-Cys Prx). The active Ac-1-Cys Prx enzyme has been purified and its properties studied. Understanding the properties of the Ac-1-Cys Prx and the ability to produce large quantities of the purified enzyme will allow its future utility in testing and developing applications in medicine or as health food.

\section{Materials and methods}

Antrodia camphorata

Fruiting bodies of $A$. camphorata, which naturally grows in the punk of $C$. kanehirai hay, were obtained from the central part of Taiwan.

\section{Total RNA preparation and cDNA synthesis}

Fresh fruiting bodies (wet weight, $1.3 \mathrm{~g}$ ) were frozen in liquid nitrogen and ground to powder in a ceramic mortar. Total RNA was prepared using TRIzol reagent (GIBCO, Frederick, MD, USA) as described before (Ken et al. 2005). The total RNA $(4.2 \mu \mathrm{g})$ was obtained. Three micrograms of the total RNA was used for cDNA synthesis 
using a ZAP-cDNA kit from Stratagene (La Jolla, CA, USA).

\section{Isolation of Ac-1-Cys Prx cDNA}

We have previously established an EST database from fruiting bodies of A. camphorata and sequenced all colonies with insert size greater than $0.4 \mathrm{~kb}$ (data not shown). The identity of Prx cDNA clone was assigned by comparing the inferred amino acid sequence in various databases using the basic local alignment search tool (BLAST).

\section{Recombinant DNA preparation}

The coding region of the Prx cDNA was amplified using two gene-specific primers. The $5^{\prime}$ primer contains the NdeI recognition site (5' GGAATT CCA TATG CCT AGC CTC CGC CTT GGA $3^{\prime}$ ), and the $3^{\prime}$ primer contains the XhoI recognition site (5' CCGCTCGAG TAC GTT GAG AGG GGT GGT TCG $3^{\prime}$ ). Using $0.1 \mu \mathrm{g}$ of $A$. camphorata cDNA as a template and 10 pmol of each $5^{\prime}$ and $3^{\prime}$ primer, a 0.7 $\mathrm{kb}$ fragment was amplified by polymerase chain reaction (PCR). The fragment was ligated into pCR2.1 and transformed into Escherichia coli TOPO10. Plasmid DNA was isolated from the clone and digested with NdeI and XhoI. The digestion products were separated on a $0.8 \%$ agarose gel. The $0.7-\mathrm{kb}$ insert DNA was gel-purified and subcloned into NdeI and XhoI sites of pET-20b $(+)$ expression vector (Novagen). The recombinant DNA was then transformed into $E$. coli $\mathrm{BL} 21(\mathrm{DE}) \mathrm{pLysS}$. The recombinant protein was overexpressed in $E$. coli and its peroxidase function checked by enzyme activity assay.

\section{Overexpression and purification of the recombinant Ac-1-Cys Prx}

The transformed E. coli containing the Ac-1-Cys Prx gene was grown at $32{ }^{\circ} \mathrm{C}$ in $200 \mathrm{ml}$ of Luria-Bertani broth containing $50 \mu \mathrm{g} / \mathrm{ml}$ ampicillin and $12.5 \mu \mathrm{g} / \mathrm{ml}$ chloramphenicol until $A_{600}$ reached 0.9. Protein expression was induced by the addition of isopropyl $\beta$-D-thiogalactopyranoside to a final concentration of $1 \mathrm{mM}$. The culture was incubated for an additional $4 \mathrm{~h}$ at $150 \mathrm{rpm}$. The cells were harvested, and soluble proteins were extracted with glass beads as described before (Ken et al. 2005). The recombinant Ac-1-Cys Prx was purified by Ni-NTA affinity chromatography as per the manufacturer's instruction (Qiagen). The purified enzyme $(6 \mathrm{ml})$ was dialyzed against $200 \mathrm{ml}$ phosphate-buffered saline (PBS) containing 1\% glycerol at $4{ }^{\circ} \mathrm{C}$ for $4 \mathrm{~h}$. Fresh PBS containing $1 \%$ glycerol was changed once during dialysis. The dialyzed sample was either used directly for analysis or stored at $-20^{\circ} \mathrm{C}$ until use.

\section{Protein concentration measurement}

Protein concentration was determined by a Bio-Rad protein assay kit (Richmond, CA, USA) using bovine serum albumin as a reference standard.

\section{Analysis of the MWs by gel filtration chromatography}

The MWs of the purified enzyme were determined by gel filtration chromatography. Purified enzyme was applied to a gel filtration column (Shodex PROTEIN KW-802.5, 8× $300 \mathrm{~mm}$; Showa Denko Co., Japan) on a high-performance liquid chromatography (HPLC) system. The protein was eluted at a flow rate of $1 \mathrm{ml} / \mathrm{min}$ with $50 \mathrm{mM}$ potassium phosphate (pH 6.8).

\section{Antioxidant activity assay}

The recombinant Ac-1-Cys Prx enzyme (0.5-2.0 $\mu \mathrm{g}$ protein) was incubated in $45-48 \mu \mathrm{l}$ buffer $(1 \mathrm{mM}$ DTT in $0.33 \times \mathrm{PBS}$ containing $5 \%$ glycerol) for $2 \mathrm{~min}$ at room temperature. The reaction was initiated by the addition of $2-5 \mu l 1 \mathrm{mM} t$-butylperoxide $(t$-BOOH; $40-100 \mu \mathrm{M})$. At 0 - and 10-min reaction times, $50 \mu \mathrm{l}$ aliquot of the reaction mixture was taken, and $20 \mu \mathrm{l}$ of $26.3 \%$ trichloroacetic acid was added to stop the reaction. The peroxidase activity was determined by following the disappearance of the peroxide substrate (the total peroxide, $2-5 \mathrm{nmol}$ at the beginning of the reaction minus the remaining amount of the $10 \mathrm{~min}$ ). The remaining peroxide content was determined as a redcolored ferrithiocyanate complex formed by the addition of $20 \mu 110 \mathrm{mM} \mathrm{Fe}(\mathrm{II})\left(\mathrm{NH}_{4}\right)\left(\mathrm{SO}_{4}\right)_{2}$ and $10 \mu \mathrm{l} 2.5 \mathrm{M} \mathrm{KSCN}$ to the $70-\mu l$ reaction mixture, which was quantified by measurement of the absorbance at $475 \mathrm{~nm}$ (Thurman et al. 1972; Kawazu et al. 2001). The Trx-dependent reduction of $t$-BOOH by Ac-1-Cys Prx was monitored using nicotinamide adenine dinucleotide phosphate (reduced form; NADPH) reduction of Trx, catalyzed by E. coli NADPH thioredoxin reductase (TrxR) (Kang et al. 1998; Kawazu et al. 2001).

\section{Enzyme characterization}

The enzyme was tested for its stability under various conditions. Aliquots of the Ac-1-Cys Prx sample were treated as follows:

1. Thermal stability. Enzyme sample was heated to $60^{\circ} \mathrm{C}$ for $0,2,4,8$, or $16 \mathrm{~min}$.

2. pH stability. Enzyme sample was adjusted to desired $\mathrm{pH}$ by adding a half-volume of buffer with different pHs: $0.2 \mathrm{M}$ citrate buffer $(\mathrm{pH} 2.2), 0.2 \mathrm{M}$ Tris- $\mathrm{HCl}$ buffer $(\mathrm{pH} 5.4,7.8$, or 9.0 ), or $0.2 \mathrm{M}$ glycine- $\mathrm{NaOH}$ 
buffer ( $\mathrm{pH}$ 10.2). Each sample was incubated at $37^{\circ} \mathrm{C}$ for $30 \mathrm{~min}$.

3. Sodium dodecyl sulfoxide effect. Sodium dodecyl sulfoxide (SDS), a protein denaturing reagent, was added to the enzyme sample to the levels of 1,2 , or $4 \%$ and incubated at $37^{\circ} \mathrm{C}$ for $30 \mathrm{~min}$.

4. Imidazole effect. During protein purification, the Ac-1Cys Prx enzyme was eluted with imidazole. Therefore, the effect of imidazole on protein activity/stability was examined. Imidazole was added to the enzyme sample to the levels of $0.2,0.4,0.8$, or $1.6 \mathrm{M}$ and incubated at $37^{\circ} \mathrm{C}$ for $30 \mathrm{~min}$.

5. Proteolytic susceptibility. The enzyme was incubated with $1 / 20$ its weight of trypsin or chymotrypsin at $\mathrm{pH} 8.0,37^{\circ} \mathrm{C}$ for a period of 10,20 , or $40 \mathrm{~min}$. In the chymotrypsin digestion, $\mathrm{CaCl}_{2}$ was added to $5 \mathrm{mM}$. Aliquots were removed at various time intervals for analysis.

After each treatment, two thirds of the sample was electrophoresed onto a $15 \%$ native polyacrylamide gel electrophoresis (PAGE) or 15\% SDS-PAGE to determine any changes in protein levels. The other one third of the sample was used for ferrithiocyanate assay to determine any changes in enzyme activity.

\section{Results}

Cloning and characterization of a cDNA encoding Ac-1-Cys Prx

Approximately 40,000 A. camphorata cDNA clones were sequenced (data not shown). Nucleotide sequences and the inferred amino acid sequences of these clones were compared with the sequences in various nucleic acid and protein data banks using the FASTN and FASTP programs, respectively. A putative 1-Cys Prx cDNA clone was identified by sequence homology to the published Prxs. The Ac-1-Cys Prx cDNA [837 bp, European Molecular Biology Laboratory (EMBL) accession no. AY870325] contains an open reading frame encoding a protein of 223 amino acid residues with calculated molecular mass of 25,081 Da. Figure 1 shows the nucleotide and the deduced amino acid sequences of the Ac-1-Cys Prx clone. Figure 2 shows the amino acid sequence alignment of the putative Ac-1-Cys Prx with 1-Cys Prx from several sources. The Ac-1-Cys Prx shared 44-58\% identity with 1-Cys Prx from Homo (Homo sapiens, P30041), Bos (Bos taurus, O77834), Rattus (Rattus norvegicus, O35244), Mus (Mus musculus, O08709), Dirofilaria (Dirofilaria immitis, O17433), and
Fig. 1 Nucleotide and deduced amino acid sequence of Ac-1Cys Prx (837 bp, EMBL accession no. AY870325). Numbers to the left refer to nucleotide and its deduced amino acid residues. The conserved Cys and surrounding residues are underlined. The asterisk denotes the translation stop signal

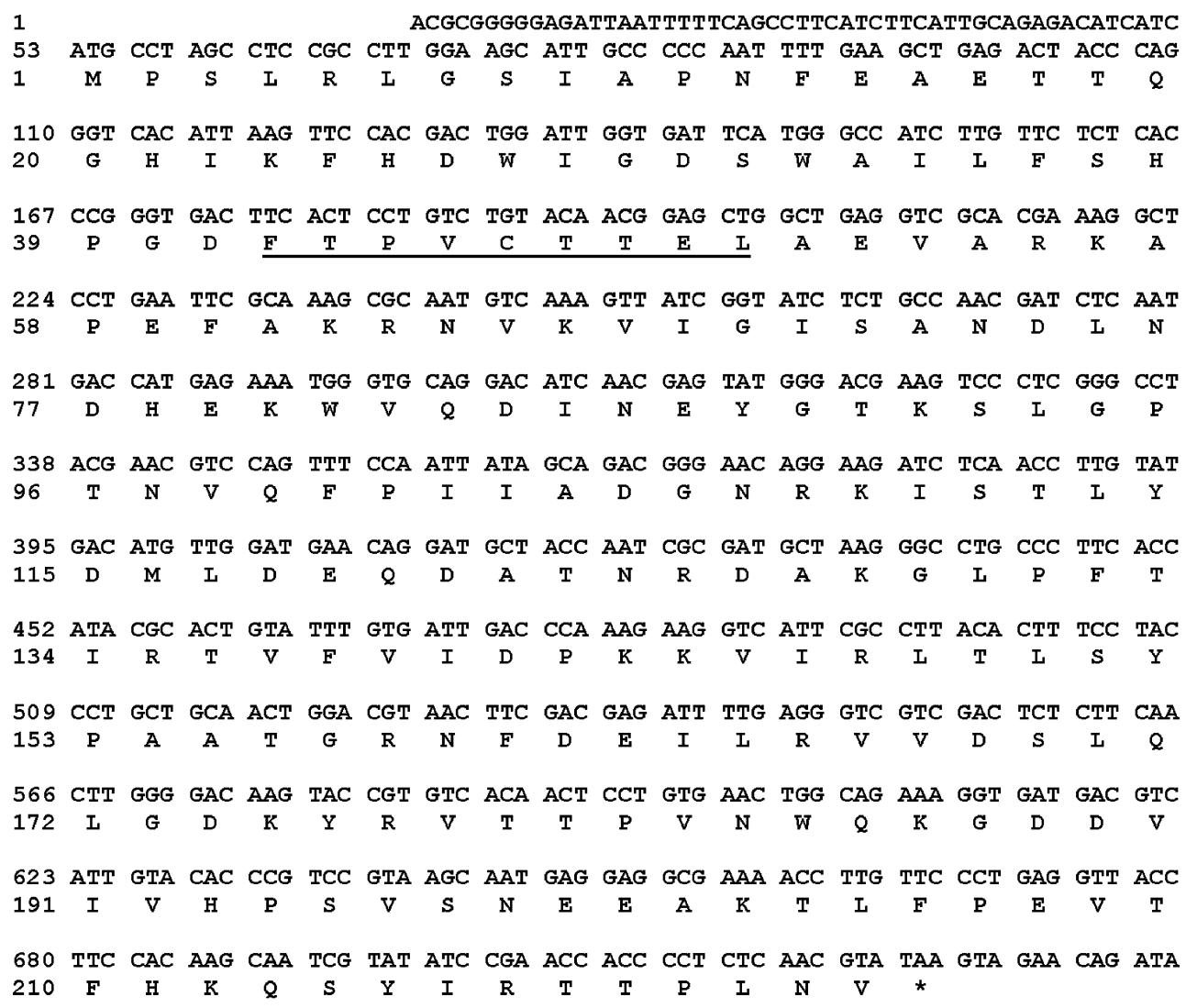

737 TGGATTTGTTATCGGATCTGTGTAACTGTATTTGTATAAGTGATGCAATCCTGAAACGTTTCTCATTTCCGCAAA 812 AAAAAAAAAAAAAAAAAAAAAAAA 837 


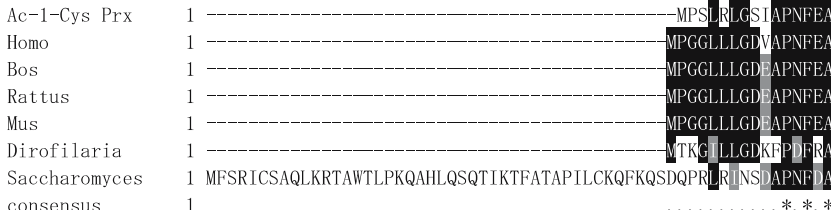

consensus

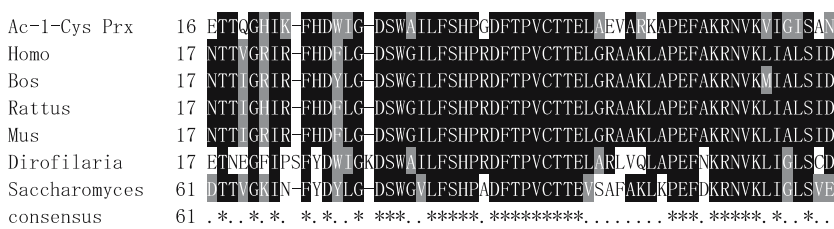

Ac-1-Cys Prx

Homo

Bos

Rattus

Mus

Dirofilaria

Saccharomyces

consensus

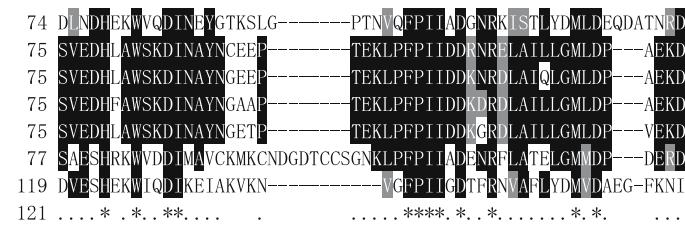

Ac-1-Cys Prx

Homo

Bos

Rattus

Mus

Dirofilaria

Saccharomyces

consensus
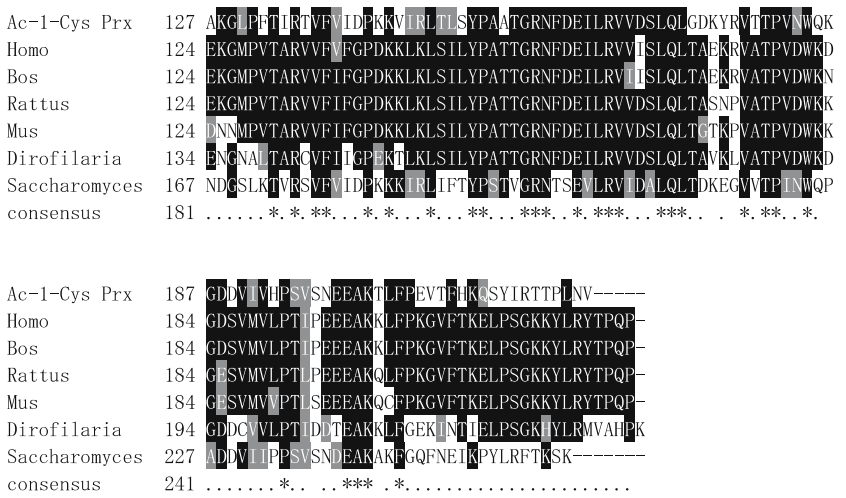

Fig. 2 Optimal alignment of the amino acid sequences of 1-Cys Prx from A. camphorata Ac-1-Cys Prx (this study), Homo (H. sapiens), Bos (B. taurus), Rattus (R. norvegicus), Mus (M. musculus), Dirofilaria (D. immitis), and Saccharomyces (S. cerevisia). Identical amino acids in all sequences are shaded black; conservative replacements are shaded gray

Saccharomyces (Saccharomyces cerevisia, P34227). As expected, many structurally or functionally important residues are conserved. The consensus sequence surrounding the conserved cysteine of 1-Cys Prx proteins (corresponding to Cys47 of human 1-Cys Prx), PVCTTE, is totally conserved. The catalytic triads $\mathrm{C} 46, \mathrm{H} 38$, and R135 (amino acid residue numbering according to Ac-1Cys Prx) representing the minimum prerequisite for peroxidatic activity (Choi et al. 1998; Hofman et al. 2002) are conserved.

\section{Expression and purification of the recombinant Ac-1-Cys Prx}

The coding region of Ac-1-Cys Prx ( $0.7 \mathrm{~kb})$ was amplified by PCR and subcloned into an expression vector, pET-20b(+), as described in "Materials and methods". Positive clones were verified by DNA sequencing. The recombinant Prx protein was overexpressed, and the total cellular proteins were analyzed by a $15 \%$ SDS-PAGE (Fig. 3, lane 1). The expression level of recombinant Prx protein was approximately $15 \%$ of total bacterial protein. The Prx, expressed as a 6 His-tagged fusion protein, was purified by affinity chromatography with nickel-chelating Sepharose. The purity of the protein was examined by SDS-PAGE (Fig. 3, lanes 4-8). The purified Prx migrates as a single band of about $25 \mathrm{kDa}$ on reducing SDS-PAGE. The presence of $25 \mathrm{kDa}$ Prx was confirmed by gel filtration chromatography (data not shown). The yield of the purified His-tagged Prx was $2.72 \mathrm{mg}$ from $200 \mathrm{ml}$ of culture. The isolated recombinant protein showed peroxidase activity in vitro as described below.

\section{Antioxidant activity of the enzyme}

The activity of the Ac-1-Cys Prx to remove $t$ - $\mathrm{BOOH}$ was evaluated using the ferrithiocyanate system. This Ac-1-Cys Prx showed no ability to remove $t$-BOOH without supplementing thiols in the reaction mixture. Such activity was promoted more efficiently if DTT was added at $1 \mathrm{mM}$ to the reaction mixture (Fig. 4a).The result indicates that DTT is capable of reducing the oxidized form of the Ac-1Cys Prx to regenerate its enzymatic activity. The Ac-1-Cys Prx catalyzed the removal of $t$ - $\mathrm{BOOH}$ in the presence of DTT in a concentration-dependent manner (Fig. 4a). This thiol peroxidase ability to remove $t$-BOOH by the Ac-1-Cys Prx protein was not supported by the presence of $1 \mathrm{mM}$ gluthathione (GSH) (Fig. 4a). The representative time course study under the substrate $(t-\mathrm{BOOH})$ concentration of $60 \mu \mathrm{M}$ was shown in Fig. 4b. The Trx-linked peroxidase

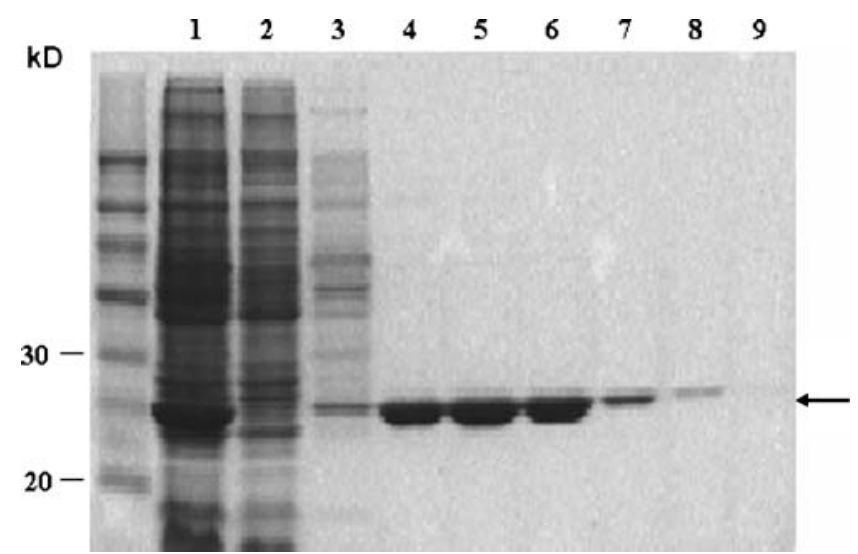

Fig. 3 Coomassie-blue-stained SDS-polyacrylamide gel showing the purification of 6His-tagged Ac-1-Cys Prx expressed in E. coli. Lane 1, crude extract from E. coli expressing the Prx; lane 2, flow-through proteins; lane 3, wash; lanes 4-9, purified Prx eluted from Ni-NTA column fractions 1-6. Molecular masses (in kilodaltons) of standards are shown at left. An arrow denotes the target protein 


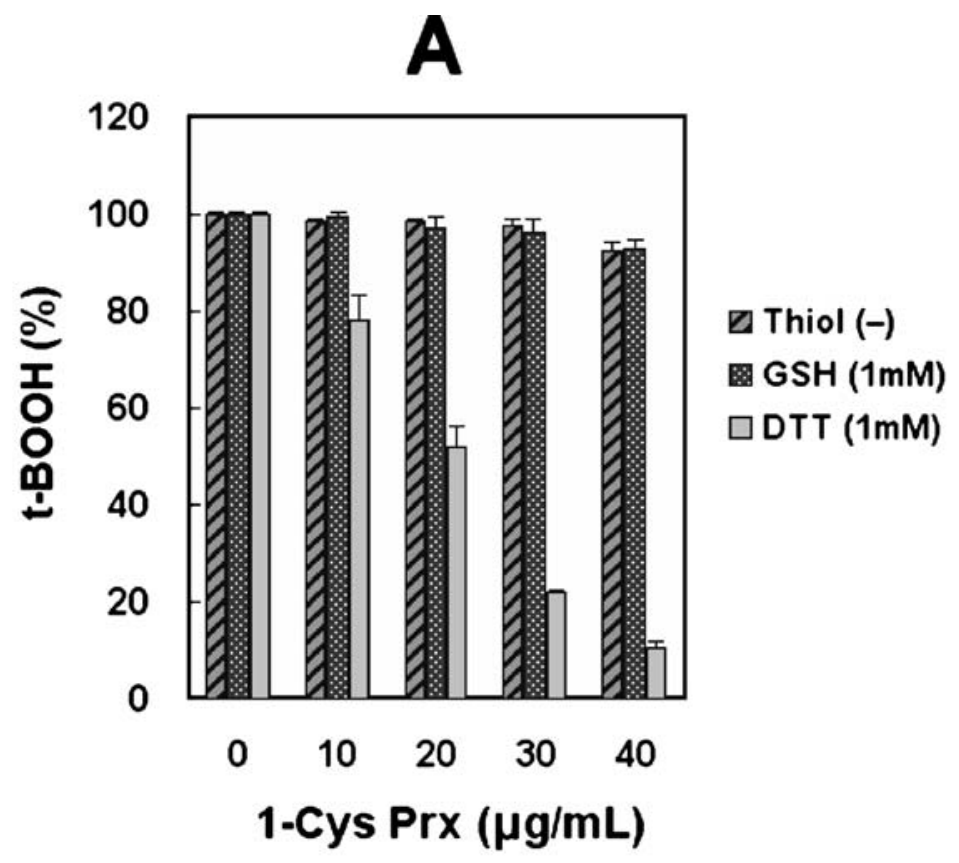

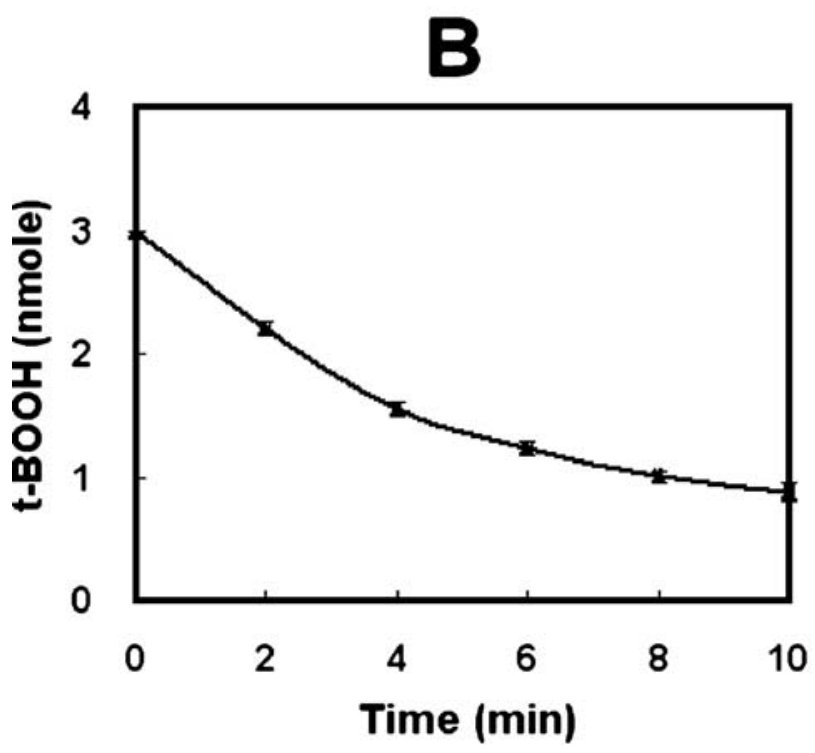

Fig. 4 Peroxidase activity of Ac-1-Cys Prx. An effect of $1 \mathrm{mM}$ DTT or $1 \mathrm{mM} \mathrm{GSH}$ (a) on the activity of the Prx to remove $t$-BOOH was examined in a $50-\mu 1$ reaction volume. Various concentrations of the Prx protein were incubated with $t$ - $\mathrm{BOOH}(60 \mu \mathrm{M})$ in the presence or absence of the indicated thiols for $10 \mathrm{~min}$. The remaining $t$ - $\mathrm{BOOH}$ in the reaction mixture was measured using the ferrithiocyanate system. The results were expressed as the percentage of $\mathrm{A}_{475}$ recorded with the Prx relative to that without the Prx. Data are means of three experiments. b Time-dependent removal of $t$-BOOH $(60 \mu \mathrm{M})$ by the Prx protein $(30 \mu \mathrm{g} / \mathrm{ml})$ with $1 \mathrm{mM}$ DTT was recorded from 2 to

activity of the Ac-1-Cys Prx was tested by monitoring the oxidation of NADPH in the presence of $E$. coli $\operatorname{Trx} / \operatorname{TrxR}$ system (Fig. 4c). After the addition of $t-\mathrm{BOOH}$, the Trx/ TrxR system with the addition of Ac-1-Cys Prx showed a little decrease in $A_{340}$, which was attributed to the oxidation of NADPH. The result suggests that the Ac-1-Cys Prx has very little TPx activity.

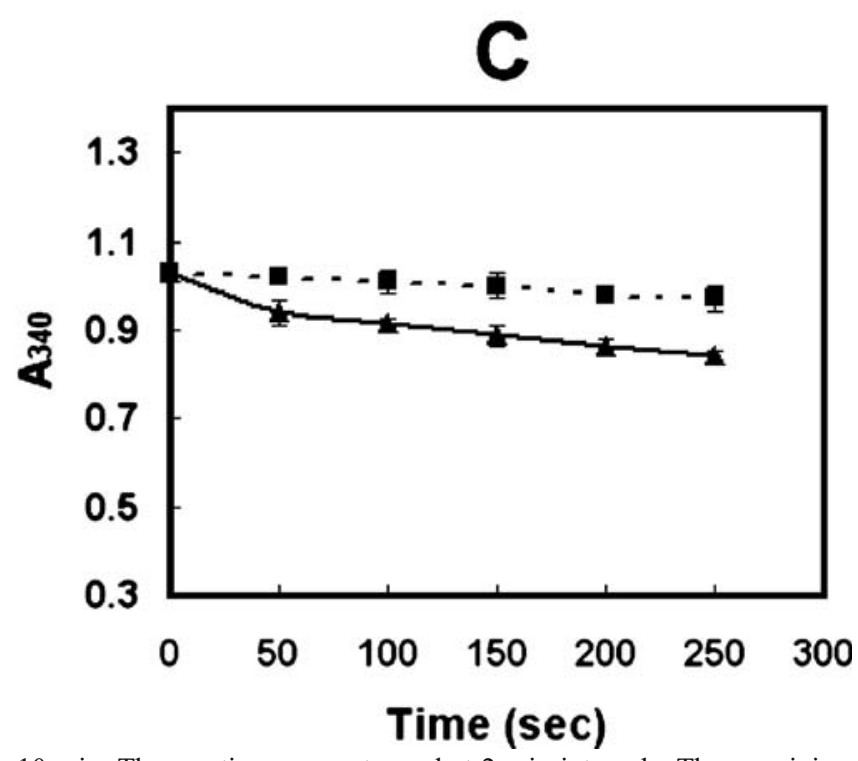

$10 \mathrm{~min}$. The reactions were stopped at 2-min intervals. The remaining $t$ - $\mathrm{BOOH}$ were expressed as nanomoles of $t-\mathrm{BOOH}$ calculated on the basis of $\mathrm{A}_{475}$ recorded at the indicated time. Data are means of three experiments. c The NADPH oxidation is coupled by the E. coli Trx and Trx R system to the Prx-mediated reduction of $t$-BOOH (dotted line). The NADPH oxidation was monitored as the decrease in $\mathrm{A}_{340}$ in a $100-\mu 1$ reaction mixture $(1.2 \mu \mathrm{M}$ TR, $8 \mu \mathrm{M}$ Trx, $0.25 \mathrm{mM}$ NADPH, $100 \mu \mathrm{g} / \mathrm{ml} \mathrm{Ac-1-Cys}$ Prx protein, $100 \mu \mathrm{M} t$-BOOH in $0.16 \times$ PBS containing 2\% glycerol). Solid line indicates absence of the Prx. Data are representative of three similar experiments

\section{Characterization of the purified Ac-1-Cys Prx}

The Ac-1-Cys Prx was characterized on its heat stability, the influence of $\mathrm{pH}$, SDS, imidazole, or proteases sensitivity. Heat stability and imidazole effects were tested because the information is useful for developing enzyme purification protocols. The data of thermostability are important for 
preparation of the enzyme as health food, which often involves processing under higher temperature during lyophilization. SDS tests may be beneficial if the enzyme is to be used in cosmetics because cosmetics often contain SDS. Protease tests were useful in understanding the effect of the digestive enzymes to the Prx and its suitability as health food.

The enzyme inactivation kinetics was performed at $60^{\circ}$ $\mathrm{C}$ as described in "Materials and methods." The total amount of protein after heating at $60^{\circ} \mathrm{C}$ did not change, as shown by the SDS-PAGE (Fig. 5a). However, the protein intensity decreased significantly after heating in the native gel (Fig. 5b). This is likely due to denaturation and aggregation of the enzyme by heat. The enzyme inactivation kinetics at $60^{\circ} \mathrm{C}$ fit the first-order inactivation rate equation $\ln \left(E_{\mathrm{t}} / E_{\mathrm{o}}\right)=-K_{\mathrm{d}} t$, where $E_{\mathrm{o}}$ and $E_{\mathrm{t}}$ represent the original activity and the residual activity after heating for time $t$, respectively. The thermal inactivation rate constant $\left(K_{\mathrm{d}}\right)$ calculated for the enzyme was 0.045 per minute at $60^{\circ} \mathrm{C}$, and the half-life of inactivation was $15.5 \mathrm{~min}$ (Fig. 5c).

The Ac-1-Cys Prx showed activity under alkaline condition with optimal $\mathrm{pH}$ at 9 (results not shown). No activity was detected at or below $\mathrm{pH} 5.4$ (results not shown). The enzyme activity was lost completely in the presence of $1 \%$ SDS or higher (results not shown). The enzyme showed a decrease in activity with increasing concentration of imidazole (Fig. 6). Approximately $70 \%$ of the Prx activity was lost in the presence of $0.4 \mathrm{M}$ imidazole or higher. The presence of $1.6 \mathrm{M}$ imidazole seemed to promote protein degradation. Therefore, during protein elution from the affinity column, one should limit the concentration of imidazole and remove it by dialysis promptly after elution.

The Ac-1-Cys Prx is sensitive to proteolytic degradation by digestive enzymes such as trypsin (Fig. 7) or chymotrypsin (results not shown). As soon as either protease was added, the Ac-1-Cys Prx activity dropped by $30-40 \%$. Very little or no activity was detected after 40 min incubation with either protease. These results were not surprising because the protein contains 25 potential trypsin cleavage sites and 18 potential chymotrypsin high specificity (Cterm to [FYW], not before $\mathrm{P}$ ) cleavage sites, or 38 chymotrypsin-low specificity (C-term to [FYWML], not before P) cleavage sites. The results suggest that the Ac-1Cys Prx is likely to be degraded if taken orally.

\section{Discussion}

Based on previous reports (Wood et al. 2003a,b), the following conclusions are drawn: (1) The $C_{P}$ is surrounded by three residues conserved in all Prx classes reported-
Fig. 5 Effect of temperature on the purified Ac-1-Cys Prx. The enzyme sample was heated at $60^{\circ} \mathrm{C}$. Aliquots of the sample were taken at $0,2,4,8$, or 16 min and analyzed by $15 \%$ SDS-PAGE $(3.6 \mu \mathrm{g}$ protein per lane, stained with Coomassie Blue) (a); $15 \%$ native PAGE $(3.6 \mu \mathrm{g}$ protein per lane, stained with Coomassie Blue) (b); Prx activity assay $(1.8 \mu \mathrm{g}$ protein per assay) (c). Data are means of three experiments
A

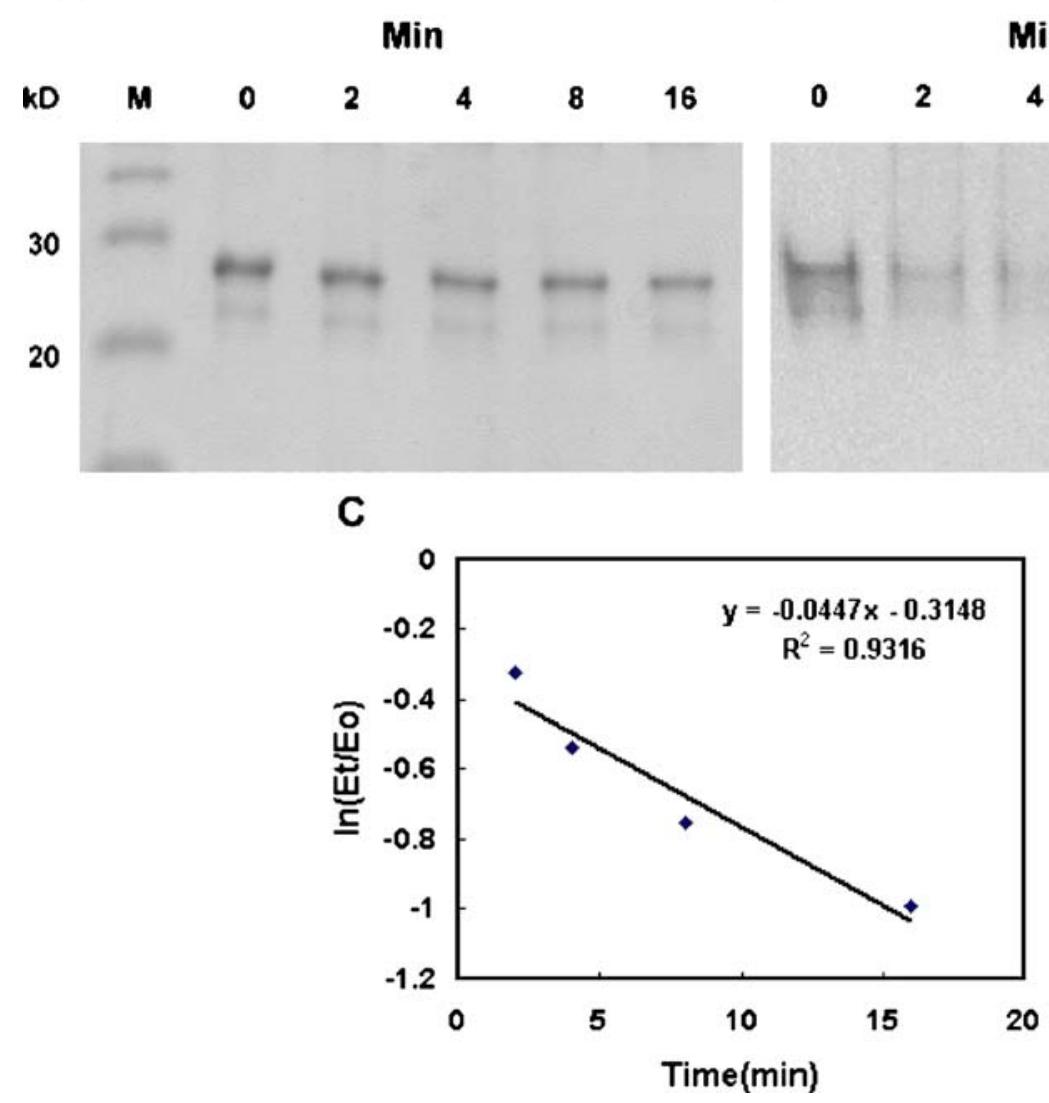




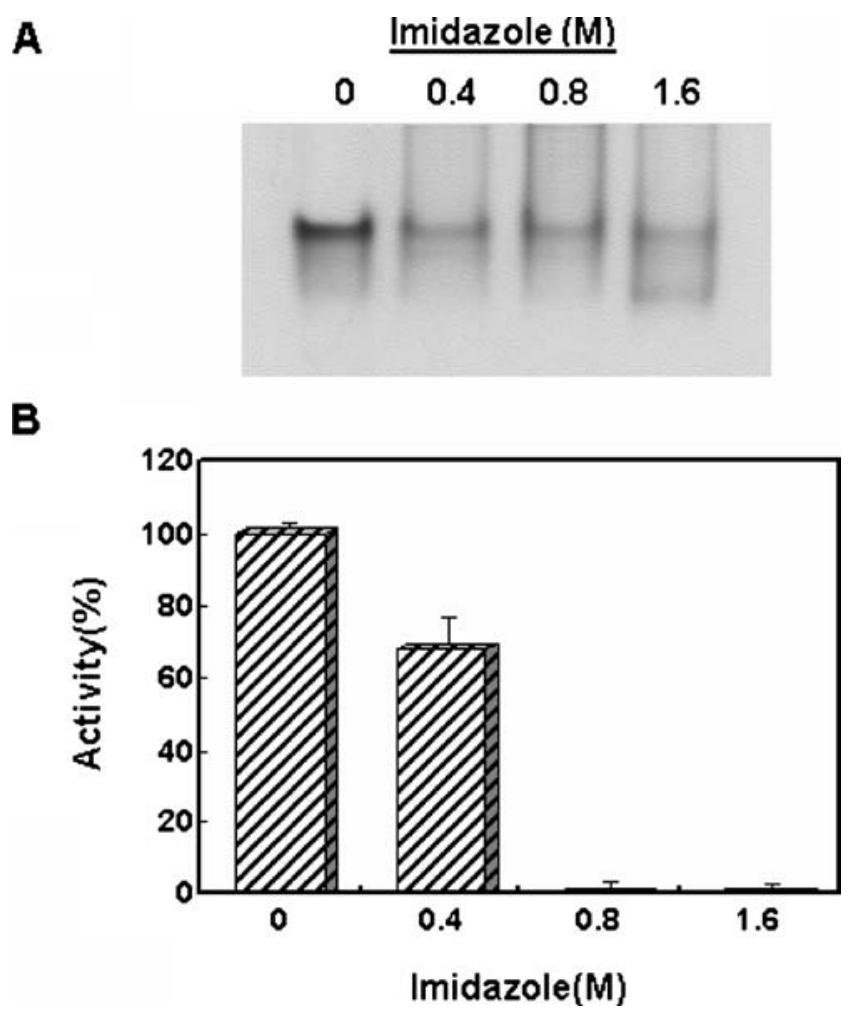

Fig. 6 Effect of imidazole on the purified Ac-1-Cys Prx. The enzyme samples were incubated with various concentration of imidazole at $37^{\circ} \mathrm{C}$ for $30 \mathrm{~min}$ and analyzed by $15 \%$ native PAGE. a Staining for protein $(3.6 \mu \mathrm{g}$ protein per lane). b Prx activity assay $(1.8 \mu \mathrm{g}$ protein per assay). Data are means of three experiments

Pro39, Thr43, and Arg125 (Ac-1-Cys Prx numbering). The Pro limits the solvent and peroxide access to $\mathrm{C}_{\mathrm{P}}$ and shields $\mathrm{C}_{\mathrm{P}}$ sulfenic acid from further oxidation by peroxides. The Thr might position the proton for abstraction by an unidentified catalytic base, and the Arg might aid this by stabilizing the growing negative charge on the sulfur. The presence of Pro39, Thr43, and Arg 125 surrounding the $C_{p}$ in the Ac-1-Cys Prx confirm the identity of the clone. (2) Phosphorylation of mammalian typical Prx (I-IV) at the conserved residue Thr89 (Ac-1-Cys Prx numbering is 90) by cyclin-dependent kinases was to decrease the peroxidase activity. The presence of a similar phosphorylation site in this Prx suggests that phosphorylation may be a common regulatory mechanism among Prxs.

1-Cys Prxs have been studied from several sources: human PrxVI (1-Cys Prx) is a cytosolic protein possessing peroxidase activity and slight phospholipase $\mathrm{A}_{2}$ activity. $\mathrm{Cys}^{47}$ at the active site is responsible for the catalytic reduction of $\mathrm{H}_{2} \mathrm{O}_{2}$ by DTT in vitro but not functional with thioredoxin or GSH (Kang et al. 1998). However, depletion of GSH diminished the activity of human PrxVI in intact cells, indicating that GSH can serve as a physiological electron donor (Manevich et al. 2002). In the present study, we showed that the Ac-1-Cys Prx can use DTT but not GSH as
A

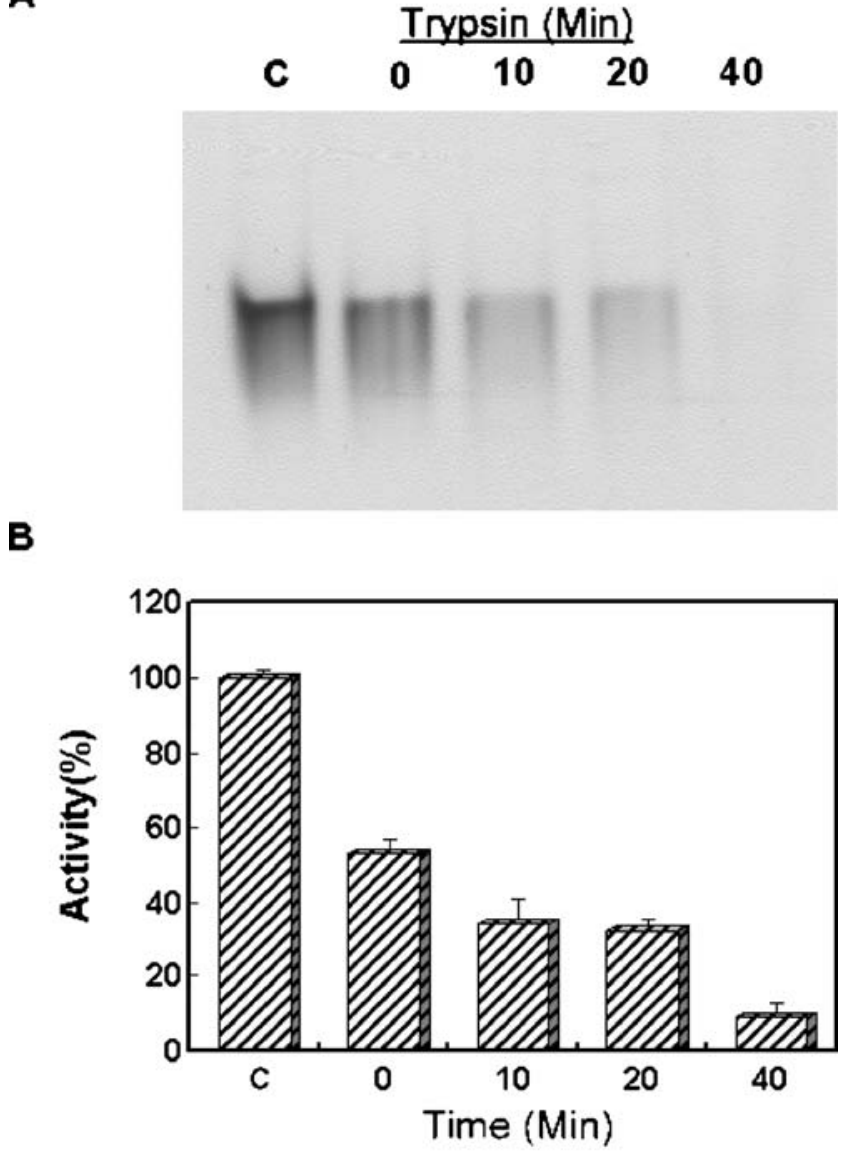

Fig. 7 Effect of trypsin on the purified Ac-1-Cys Prx. The enzyme samples were incubated with trypsin at $37^{\circ} \mathrm{C}$ for various times and analyzed by $15 \%$ native PAGE. a Staining for protein $(3.6 \mu \mathrm{g}$ protein per lane). b To assay activity for protein $(1.8 \mu \mathrm{g}$ protein per time interval). Data are means of three experiments

electron donor (Fig. 4a). In the presence of E. coli $\operatorname{Trx} / \operatorname{TrxR}$ system (Fig. 4c), the Ac-1-Cys Prx showed a slight decrease in $\mathrm{A}_{340}$, suggesting that Ac-1-Cys Prx has little TPx activity. Whether 1-Cys Prx uses GSH or Trx as a substrate in vivo for reduction of peroxides remains to be investigated.

The fruiting body of $A$. camphorata is well known in Taiwan as a folk medicine for treating cancer and inflammation. Very little is known about the mode of actions of its biological effects. We have been actively searching for the important physiologically active components in $A$. camphorata that are responsible for its medicinal efficacy. In folk therapy, the whole mushroom was ground to powder and then taken orally. The physiologically active components in A. camphorata should be stable in the digestive system and should be absorbed to be effective orally. Although several Prxs have been implicated as either therapeutic targets or diagnostic biomarkers for major diseases, it is not clear if Ac-1-Cys Prx is an active component in $A$. camphorata when ingested orally. The proteases' digestion results (Fig. 7) and the 
instability of Ac-1-Cyc Prx under acidic pH suggest that the enzyme may be degraded to small peptides in the digestive system. Whether the degraded peptides still possess the antioxidant activities or if they may be absorbed by the digestive system remains to be investigated. Other characterized properties of the Ac-1-Cys Prx included its thermostability (retained $50 \%$ activity after heating at $60{ }^{\circ} \mathrm{C}$ for $15.5 \mathrm{~min}$, as shown in Fig. 5), the stability under alkaline $\mathrm{pH}$ (stable from 7.8 to 10.2 ), and the stability in the presence of $0.4 \mathrm{M}$ imidazole (retained $70 \%$ activity).

Recently, we have successfully overexpressed and purified Ac-1-Cys Prx in a yeast expression system (results not shown). An enzyme isolated from a yeast expression system is superior to E. coli expression system because the yeast expression system is free of endotoxin such as lipopolysaccharide. Understanding the properties of the Ac-1-Cys Prx and the ability to produce large quantities of the purified enzyme free of endotoxin will allow us to test and develop its applications in medicine or as health food.

Acknowledgement This work was partially supported by the National Science Council of the Republic of China under grant NSC 94-2313-B-019-028 to C.-T. L.

\section{References}

Bryk R, Griffin P, Nathan C (2000) Peroxynitrite reductase activity of bacterial peroxiredoxins. Nature 407:211-215

Chae HZ, Uhm TB, Rhee SG (1994) Dimerization of thiol-specific antioxidant and the essential role of cysteine 47. Proc Natl Acad Sci USA 91:7022-7026

Choi HJ, Kang SW, Yang CH, Rhee SG, Ryu SE (1998) Crystal structure of a novel human peroxidase enzyme at $2.0 \AA$ resolution. Nat Struct Biol 5:400-406

Chon JK, Choi J, Kim SS, Shin W (2005) Classification of peroxiredoxin subfamilies using regular expressions. Genomics Inf 3:55-60

Dietz KJ (2003) Plant peroxiredoxins. Annu Rev Plant Biol 54:93107

Ellis HR, Poole LB (1997) Roles for the two cysteine residues of AhpC in catalysis of peroxide reduction by alkyl hydroperoxide reductase from Salmonella typhimurium. Biochemistry 36:1334913356

Geiben-Lynn R, Kursar M, Brown NV, Addo MM, Shau H, Lieberman J, Luster AD, Walker BD (2003) HIV-1 antiviral activity of recombinant natural killer cell enhancing factors, NKEF-A and NKEF-B, members of the peroxiredoxin family. J Biol Chem 278:1569-1574

Gems D, McElwee JJ (2003) Microarraying mortality. Nature 424:259-261

Hillas PJ, del Alba FS, Oyarzabal J, Wilks A, Ortiz De Montellano PR (2000) The AhpC and AhpD antioxidant defense system of Mycobacterium tuberculosis. J Biol Chem 275:18801-18809

Hofmann B, Hecht HJ, Flohe L (2002) Peroxiredoxins. Biol Chem 383:347-364

Hseu YC, Yang HL, Lai YC, Lin JG, Chen GW, Chang YH (2004) Induction of apoptosis by Antrodia camphorata in human premyelocytic leukemia HL-60 cells. Nutr Cancer 48:189-197
Hsiao G, Shen MY, Lin KH, Lan MH, Wu LY, Chou DS, Lin CH, Su $\mathrm{CH}$, Sheu JR (2003) Antioxidative and hepatoprotective effects of Antrodia camphorata extract. J Agric Food Chem 51:3302-3308

Hsu YL, Kuo YC, Kuo PL, Ng LT, Kuo YH, Lin CC (2005) Apoptotic effects of extract from Antrodia camphorata fruiting bodies in human hepatocellular carcinoma cell lines. Cancer Lett 221:77-89

Immenschuh S, Baumgart-Vogt E (2005) Peroxiredoxins, oxidative stress, and cell proliferation. Antioxid Redox Signal 7:768-777

Jang HH, Lee KO, Chi YH, Jung BG, Park SK, Park JH, Lee JR, Lee SS, Moon JC, Yun JW, Choi YO, Kim WY, Kang JS, Cheong GW, Yun DJ, Rhee SG, Cho MJ, Lee SY (2004) Two enzymes in one, two yeast peroxiredoxins display oxidative stress-dependent switching from a peroxidase to a molecular chaperone function. Cell 117:625-635

Kang SW, Baines IC, Rhee SG (1998) Characterization of a mammalian peroxiredoxin that contains one conserved cysteine. J Biol Chem 273:6303-6311

Kang SW, Rhee SG, Chang TS, Jeong W, Choi MH (2005) 2-Cys peroxiredoxin function in intracellular signal transduction: therapeutic implications. Trends Mol Med 11:571-578

Kawazu SI, Komaki K, Tsuji N, Kawai S, Ikenoue N, Hatabu T, Ishikawa H, Matsumoto Y, Himeno K, Kano S (2001) Molecular characterization of a 2-Cys peroxiredoxin from the human malaria parasite Plasmodium falciparum. Mol Biochem Parasitol 116:73-79

Ken CF, Hsiung TM, Huang ZX, Juang RH, Lin CT (2005) Characterization of $\mathrm{Fe} / \mathrm{Mn}$-superoxide dismutase from diatom Thallassiosira weissflogii: cloning, expression, and property. J Agric Food Chem 53:1470-1474

Manevich Y, Sweitzer TD, Pak JH, Feinstein SI, Muzykantov VR, Fisher AB (2002) 1-Cys peroxiredoxin overexpression protects cells against phospholipid peroxidation-mediated membrane damage. Proc Natl Acad Sci USA 99:11599-11604

Neumann CA, Krause DS, Carman CV, Das S, Dubey DP, Abraham JL, Bronson RT, Fujiwara Y, Orkin SH, Van Etten RA (2003) Essential role for the peroxiredoxin Prdx1 in erythrocyte antioxidant defence and tumour suppression. Nature 424:561-565

Pak JH, Manevich Y, Kim HS, Feinstein SI, Fisher AB (2002) An antisense oligonucleotide to 1-cys peroxiredoxin causes lipid peroxidation and apoptosis in lung epithelial cells. J Biol Chem 277:49927-49934

Rhee SG, Kang SW, Jeong W, Chang TS, Yang KS, Woo HA (2005a) Intracellar messenger function of hydrogen peroxide and its regulation by peroxiredoxins. Curr Opin Cell Biol 17:183-189

Rhee SG, Yang KS, Kang SW, Woo HA, Chang TS (2005b) Controlled elimination of intracellular $\mathrm{H}_{2} \mathrm{O}_{2}$ : regulation of peroxiredoxin, catalase, and glutathione peroxidase via posttranslational modification. Antioxid Redox Signal 7:619-626

Song TY, Yen GC (2003) Protective effects of fermented filtrate from Antrodia camphorata in submerged culture against $\mathrm{CCl}_{4}$-induced hepatic toxicity in rats. J Agric Food Chem 51:1571-1577

Thurman RG, Ley HG, Scholz R (1972) Hepatic microsomal ethanol oxidation. Hydrogen peroxide formation and the role of catalase. Eur J Biochem 25:420-430

Wang X, Phelan SA, Forsman-Semb K, Taylor EF, Petros C, Brown A, Lerner CP, Paigen B (2003) Mice with targeted mutation of peroxiredoxin 6 develop normally but are susceptible to oxidative stress. J Biol Chem 278:25179-25190

Wood ZA, Poole LB, Karplus PA (2003a) Peroxiredoxin evolution and the regulation of hydrogen peroxide signaling. Science 300:650-653

Wood ZA, SchrÖder E, Harris JR, Poole LB (2003b) Structure, mechanism and regulation of peroxiredoxins. Trends Biochem Sci $28: 32-40$ 